\title{
Effects of Salinity on Demographic Traits of the Rotifer (Brachionus rotundiformis)
}

\author{
Reza Malekzadeh Viayeh and Choon Bok Song* \\ Laboratory of Fish Genetics and Breeding, College of Ocean Science, \\ Cheju National University, Jeju 690-756, Korea
}

\begin{abstract}
Six demographic parameters including life span (LS), maturation time (MT), net reproduction rate $(R o)$, mean generation length $(G)$, innate capacity for increase $\left(r_{m}\right)$ and finite rate of increase $(\lambda)$ were estimated in the rotifer (Brachionus rotundiformis) cultured at three salinities of 5,20 and $34 \mathrm{PSU}$ and under a constant temperature of $28^{\circ} \mathrm{C}$. The maximum life spans at salinities of 5, 20 and 34 PSU were 17, 12 and 13 days, respectively. The shortest maturation time $(24 \mathrm{hr})$ was recorded at $5 \mathrm{PSU}$, and the rotifer at 20 PSU showed a most delayed maturation $(192 \mathrm{hr})$. The maximum reproduction rate was 42 offspring per female in rotifer cultured at s PSU, while the longest generation length (8 days) was observed at 20 PSU. Maximum and minimum values of $r_{\mathrm{m}}$ ( 1.56 and 0.46 individual per day) and $\lambda$ (6.67 and 1.70 individuals per day) were calculated at 5 and 34 PSU, respectively. Salinity also showed strong effect on correlation of the demographic traits examined. ANOVA revealed significant differences $(\mathrm{P}<0.05)$ between demographic parameters of the rotifer at the three salinity condition. Considering the higher values of life span, innate capacity and finite rate of increase, and sho:test maturation time at $5 \mathrm{PSU}$, the rotifer we examined had a higher reproductive potential and longer life span at 5 PSU rather than at 20 or 34 PSU.
\end{abstract}

Key words: Brachionus rotundiformis, Demographic parameters, Rotifer, Salinity

\section{Introduction}

Rotifer ras been used for the study of laboratory population dynamics because of its small size (generally less than $500 \mu \mathrm{m}$ ) and short life cycle (Yoshinaga et al., 2003). Using rotifers as a larval food source has become common in many fish hatcheries throughout the world (Fielder et al., 2000). Several studies have shown that salinity, temperature, food type and food concentration are the most critical factors affecting the life history traits of rotifers (Smith and Enesco, 1982a; Sawada and Carlson, 1987; Cabrera et al., 19 3; Oltra and Todoli, 1997; Oltra et al., 2000; Treese and Davis, 2000; Yoshinaga et al., 2000; Bosque e: al, 2001). However, there are some difference:; in their results with regard to relative importanciz and priority among these factors. For example, Treece and Davis (2000) concluded that temperature had more significant effect than salinity on growth rate of Branchionus plicatilis, while Fielder

*Corresponding author: cbsong@cjeju.ac.kr et al. (2000) found that the effect of salinity on the rotifers (B. plicatilis and B. rotundiformis) was greater than that of temperature. Rotifers are osmo-conformers that can tolerate salinities ranging from 1-97 PSU (Fielder et al., 2000), while their optimum reproduction occurs below 35 PSU (Yoshinaga et al., 2000). Owing to their euryhalinity and ability to feed on a variety of foods, $B$. plicatilis and $B$. rotundiformis have been easily cultured at high levels of production (Bosque et al., 2001) and thus they have been routinely used as first feed organisms in marine aquaculture. Although several studies have been conducted on the biological aspects of $B$. rotundiformis and classified it as either super small (SS) type (Cabrera et al., 1993; Rumengan et al., 1998) or small (S) type (Fukusho, 1989; Fu et al., 1991a, b; Hirayama and Rumengan, 1993; Park and Hur, 1996a,b), only a few reports are available on the demographic characteristics of this species (Cabrera et al, 1993; Rumengan et al., 1998). Thus, we aimed to investigate the effect of salinities on six demographic parameters of the Cheju rotifer strain (B. rotundiformis). 


\section{Materials and Methods}

Specimens, cultures and monitoring

$B$. rotundiformis were collected from the tide pools located in Jeju island, Korea. Rotifers were isolated selectively and were cultured in 6-well tissue culture plates at 5 PSU. To obtain genetically identical clonal population, we started rotifer culture with one individual and propagated it. Then, the rotifers were acclimated serially from 5 to 20 and finally to 34 PSU during the period of 2 months. To make the media of different salinities, we used filtered and autoclaved seawater diluted with distilled water. Rotifers were fed daily with the freshwater alga Chlorella sp. at a concentration of $5.2 \times 10^{5}$ cells $/ \mathrm{mL}$. Experiments were started using the newly hatched females with a mean age of $1 \mathrm{hr}$. The number of individuals studied at salinities of 5, 20 and 35 PSU, was 100,85 and 70 , respectively. Culture plates containing rotifers were maintained in an incubator at $28^{\circ} \mathrm{C}$. Each of the culture plate was checked twice a day (9 AM and 9 PM) for the maternal female and her offspring under a microscope. At each check, the newly hatched rotifers were counted and removed by a micropipette.

\section{Calculation of demographic parameters}

For each individual, the cohort life table or agespecific life table was calculated by using age classes (x) and age specific survival rate or proportion surviving at start of age interval $\left(l_{x}\right)$, age specific birth rate or number of female offspring per female aged $x\left(m_{x}\right)$. The data of $1_{x}$ and $m_{x}$ were used to calculate the demographic parameters in this study. Four parameters were calculated by using following formulas (see Krebs, 1978): Net reproduction rate $\left(\mathrm{R}_{0}\right.$, offspring per female $)=\sum_{0}^{\infty} 1_{x} m_{x}$; Mean length of generation $(\mathrm{G}$, day $)=\sum \mathrm{l}_{\mathrm{x}} \mathrm{m}_{\mathrm{x}} \mathrm{x} / \sum \mathrm{l}_{\mathrm{x}} \mathrm{m}_{\mathrm{x}}$; Innate capacity for increase $\left(r_{m}\right.$, individuals per day $)=\log _{e}\left(R_{o}\right) / G$; Finite rate of increase $\left(\lambda\right.$, individuals per day) $=\mathrm{er}_{\mathrm{m}}$. To calculate the demographic parameters, Math Cad 4.0 mathematics software were used.

\section{Statistical analysis}

Statistical analyses were performed by using SYSTAT 10 (SPSS, Inc.). With demographic factors observed or estimated at different salinities, analysis of variance (ANOVA) were performed at a $5 \%$ significant level. To detect differences between any pairs of mean within each parameter after ANOVA, the subsequent pairwise multiple comparisons were performed by the Tukey test (Tukey, 1953).

\section{Results}

\section{General analysis}

The values of six demographic parameters of the rotifer $B$. rotundiformis calculated at three salinities are summarized in Table 1. The maximum life span was 17 days at 5 PSU and the minimum was 0.5 day at 34 PSU, and the lower the salinity, the longer the rotifer lived (Fig. 1). Since samples were checked every $12 \mathrm{hr}$, some individuals that were not alive at first observation were considered to have a life span of 0.5 day. Thus, the results of life span might

Table 1. Demographic parameters of Brachionus rotundiformis measured at three different salinities

\begin{tabular}{|c|c|c|c|c|c|c|c|}
\hline $\begin{array}{l}\text { Salinity } \\
\text { (PSU) }\end{array}$ & & $\begin{array}{l}\text { Life span } \\
\text { (day) }\end{array}$ & $\begin{array}{c}\text { Maturation } \\
\text { time } \\
\text { (hr) }\end{array}$ & $\begin{array}{l}\text { Net } \\
\text { reproduction } \\
\text { rate } \\
\text { (off./female) }\end{array}$ & $\begin{array}{c}\text { Mean } \\
\text { generation } \\
\text { length } \\
\text { (day) }\end{array}$ & $\begin{array}{c}\text { Innate } \\
\text { capacity } \\
\text { for increase } \\
\text { (ind./day) }\end{array}$ & $\begin{array}{c}\text { Finite } \\
\text { rate of } \\
\text { increase } \\
\text { (ind./day) }\end{array}$ \\
\hline \multirow{3}{*}{$\begin{array}{c}5 \\
(n=100)\end{array}$} & Mean $\pm S D$ & $5.94 \pm 3.81^{a}$ & $42.8 \pm 12.9^{A}$ & $12.55 \pm 11.67^{\mathrm{a}}$ & $3.99 \pm 1.40^{\mathrm{A}}$ & $1.56 \pm 0.83^{a}$ & $6.67 \pm 5.77^{A}$ \\
\hline & Min & 0.5 & 24 & 0 & 1.50 & 0.12 & 1.13 \\
\hline & Max & 1.7 & 84 & 42 & 7.75 & 3.32 & 27.70 \\
\hline \multirow{3}{*}{$\begin{array}{c}20 \\
(n=85)\end{array}$} & Mean \pm SD & $4.58 \pm 3.17^{b}$ & $60.2 \pm 28.9^{\mathrm{B}}$ & $5.20 \pm 5.99^{b}$ & $4.25 \pm 1.54^{\mathrm{A}}$ & $0.80 \pm 0.47^{b}$ & $2.50 \pm 1.46^{\mathrm{B}}$ \\
\hline & Min & 0.5 & 36 & 0 & 1.75 & 0.11 & 1.12 \\
\hline & Max & 12 & 192 & 24 & 8.00 & 2.26 & 9.62 \\
\hline \multirow{3}{*}{$\begin{array}{c}34 \\
(n=70)\end{array}$} & Mean $\pm S D$ & $3.54 \pm 2.43^{b}$ & $39.7 \pm 21.6^{\mathrm{B}}$ & $1.90 \pm 2.74^{c}$ & $3.26 \pm 1.35^{B}$ & $0.46 \pm 0.35^{c}$ & $1.70 \pm 1.00^{\mathrm{B}}$ \\
\hline & Min & 0.5 & 36 & 0 & 1.50 & 0.10 & 1.10 \\
\hline & $\operatorname{Max}$ & 13 & 132 & 13 & 7.55 & 1.99 & 7.28 \\
\hline
\end{tabular}

Different superscript letters at the same column data indicate that they are statistically different form each other $(\mathrm{P}<0.05)$; Adjacent columns are distinguished with each other by capital and small superscript letters. $\mathrm{n}$ : the number of individuals examined; off./female: offspring per female; ind./day: individuals per day. 


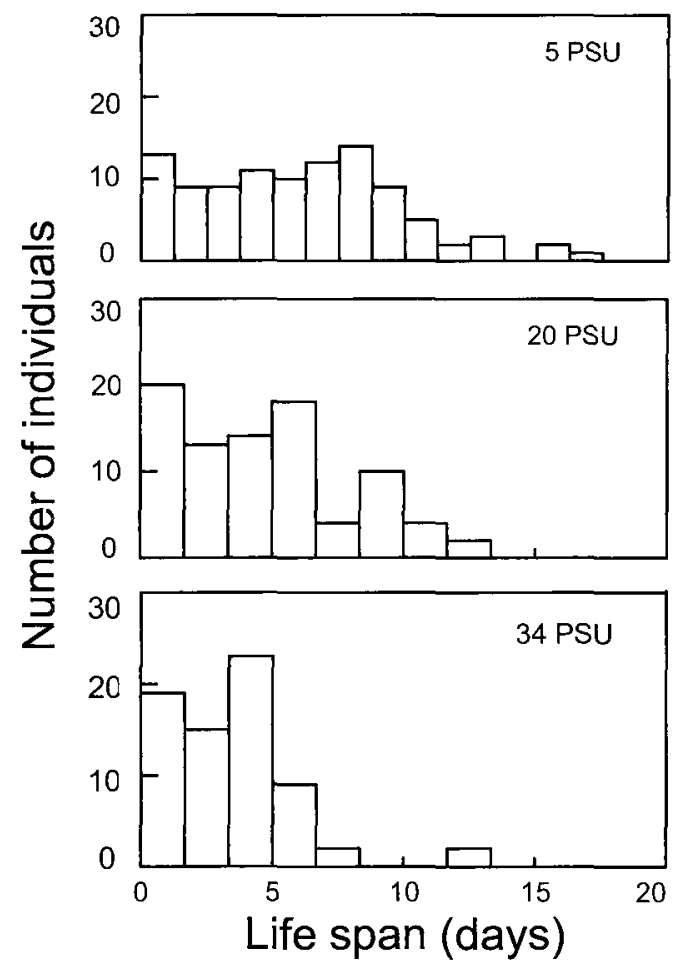

Fig. 1. Life span distribution of Brachionus rotundiformis cultured at different salinities.

be slightly different if the observation intervals were closer. The minimum maturation time was $24 \mathrm{hr}$ at 5 PSU and $36 \mathrm{hr}$ at both 20 and $34 \mathrm{PSU}$, while the maximum was $84 \mathrm{hr}$ at $5 \mathrm{PSU}, 192 \mathrm{hr}$ at $20 \mathrm{PSU}$ and $132 \mathrm{hr}$ at $\vdots 4 \mathrm{PSU}$ (Table 1). Mean maturation time was much shorter at $5 \mathrm{PSU}(42.8 \mathrm{hr})$ than those at $20(60.2 \mathrm{~h} \cdot)$ and 34 PSU $(59.7 \mathrm{hr})$. Thus, there was obvious difference between 5 PSU and other salinities, but not between 20 and 34 PSU (Fig. 2). The maximum reproduction rate was 42 offspring per female at 5 PSU, com sared to 24 and 13 offspring per female at 20 and $34 \mathrm{PSU}$, respectively. When reproduction rates were calculated, the individuals that died before maturity, were given with a reproduction rate of 0 . The maxirum mean length of generation was 8 days at $20 \mathrm{PSU}$, although the maximum and minimum mean length of generation at all three salinities differed little. The highest values of both innate capacity for increase $\left(\mathrm{r}_{\mathrm{m}}=3.32\right.$ individuals per day) and finite rate of increase $(\lambda=27.70$ individuals per day) were recorded at salinity of 5 PSU, while the lowest values of these two intrinsic parameters $\left(\mathrm{r}_{\mathrm{m}}=0.10\right.$ and $\left.\lambda=1.10\right)$ were observed at salinity of 34 PSU.

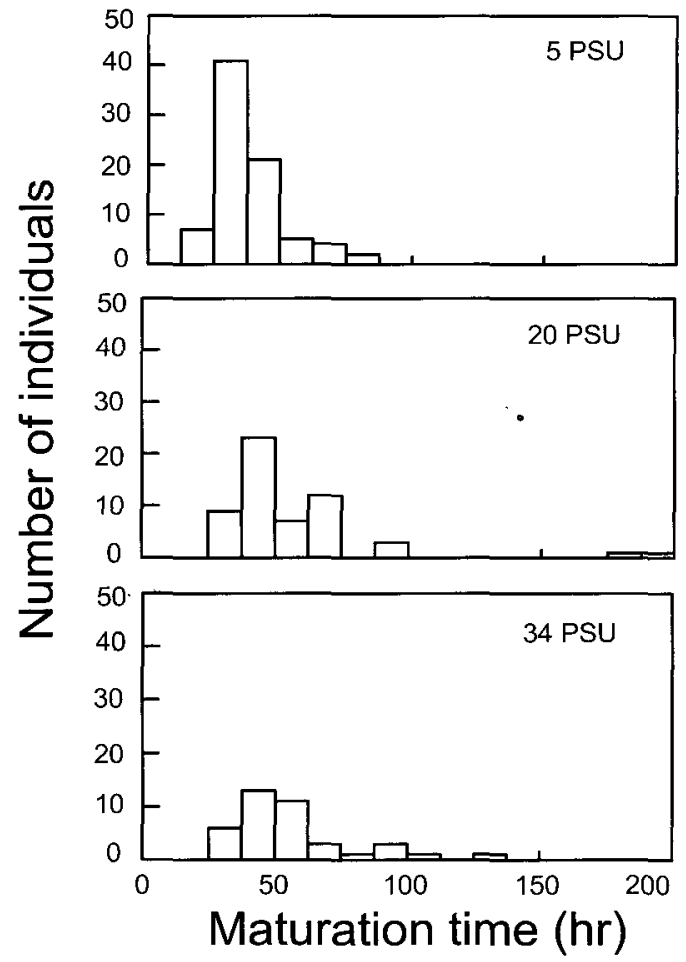

Fig. 2. Distribution of maturation time of Brachionus rotundiformis at different salinities.

\section{Analysis of variance and multiple comparison test}

ANOVA showed that there were highly significant differences among salinities in each of six demographic parameters (all, $\mathrm{P}<0.005$ ). According to multiple comparisons for detecting differences between any pair of means, there were significant differences observed in most of pairwise comparisons with two exceptions (Table 1). Life span of the rotifers was obviously different between 5 PSU and $20 \mathrm{PSU}$ $(\mathrm{P}<0.05)$, or between $5 \mathrm{PSU}$ and $34 \mathrm{PSU}(\mathrm{P}<0.001)$, but not between $20 \mathrm{PSU}$ and $34 \mathrm{PSU}(\mathrm{P}=0.12)$. Although there was difference between maturation time at 5 PSU and 20 PSU ( $<<0.001)$, or 5 PSU and $34 \mathrm{PSU} \quad(\mathrm{P}<0.001)$, no statistical difference was observed between the values of this parameter at $20 \mathrm{PSU}$ and $34 \mathrm{PSU}(\mathrm{P}=0.99)$. Net reproduction rates were significantly different at $5 \mathrm{PSU}$ vs. $20 \mathrm{PSU}$ $(\mathrm{P}<0.001), 5 \mathrm{PSU}$ vs. $34 \mathrm{PSU}(\mathrm{P}<0.001)$ and $20 \mathrm{PSU}$ vs. 34 PSU $(P<0.05)$. Mean generation length of the rotifers at two salinities, 5 PSU and 20 PSU, did not show notable difference $(\mathrm{P}=0.55)$, while there was meaningful difference between generation length of the individuals at $5 \mathrm{PSU}$ and $34 \mathrm{PSU}(\mathrm{P}<0.05)$, or between $20 \mathrm{PSU}$ and $34 \mathrm{PSU}(\mathrm{P}<0.005)$. In case of 
$\mathrm{rm}$, differences were detected for all possible comparisons in $5 \mathrm{PSU}$ vs. $20 \mathrm{PSU}(\mathrm{P}<0.001), 5 \mathrm{PSU}$ and 34 PSU $(\mathrm{P}<0.001)$ and 20 PSU and 34 PSU $(\mathrm{P}<0.05)$. The values of finite rate of increase exhibited considerable differences between $5 \mathrm{PSU}$ and $20 \mathrm{PSU}$ $(\mathrm{P}<0.001)$, or between 5 PSU and 34 PSU $(\mathrm{P}<0.001)$, but not between 20 PSU and 34 PSU ( $\mathrm{P}=0.61)$.

\section{Correlation analysis}

The overall result of correlation analysis between demographic parameters we observed or estimated is shown in Table 2. As three estimated parameters $\left(\mathrm{G}, \mathrm{r}_{\mathrm{m}}\right.$, and $\lambda$ ) are calculated based on $\mathrm{R}_{\mathrm{o}}$ (see the formulas in the text), correlation between these parameters are not completely independent. Thus, we focused on correlation between two observed parameters (LS and MT), and between these two parameters and other four estimated parameters. As shown in Table 2, there were strong correlations between life span and net reproduction rate (Fig. 3, $r=0.80$ to 0.89 ), or that between life span and mean length of generation $(\mathrm{r}=0.81$ to 0.90$)$. Correlations between life span and other two estimated parameters $\left(r_{m}\right.$, and $\left.\lambda\right)$ were relatively weak $(r=0.30$ to 0.63$)$. Among these correlations, there are some tendencies of decreasing correlation with increasing the salinity. Life span and maturation time were not much correlated each other at all salinities examined $(\mathrm{r}=$ -0.22 to 0.14 ) and its pairwise plotting is shown in
Fig. 4. Interestingly, although correlations between maturation time and other estimated parameters were not obvious ( $\mathrm{r}=-0.57$ to 0.49 ), all results revealed negative correlations except the case of maturation time vs. mean generation length.

\section{Discussion}

Cheju rotifer strain of $B$. rotundiformis used in this study was first reported by Song et al. (1999) who investigated the effect of salinity, temperature and clonal difference on rotifer size. Several comparative studies have shown that $B$. rotundiformis had more tolerance and higher growth rate at relatively higher temperatures and lower salinity than $B$. plicatilis (Cabrera et al., 1993; Fielder et al., 2000). The strain used in this study also showed large tolerance in high temperature (up to $41^{\circ} \mathrm{C}$ ) and low salinity (down to $0.5 \mathrm{PSU}$ ) under a constant temperature of $28^{\circ} \mathrm{C}$ (unpublished data). Thus, we used this rotifer as a first feed organism for the freshwater fish such as zebrafish. Considering their life span, rotifers can be regarded as short lived animals. The previous studies reported that the maximum longevities of different rotifer species were 4-6 days in Asplanchna brightwelli (Enesco et al., 1990), 14.5 days in an ultra small type of $B$. plicatilis (Cabrera et al., 1993) and $>25$ days for Philodina roseola (Smith and Enesco, 1982b). In this study, the maxi-

Table 2. Pearson correlation matrix between demographic parameters of Brachionus rotundiformis observed or estimated at different salinities (LS, life span; MT, maturation time; $R_{0}$, net production rate; $G$, mean length of generation; $r_{m}$, innate capacity of increase; $\lambda$, finite rate of increase)

\begin{tabular}{|c|c|c|c|c|c|c|c|}
\hline $\begin{array}{l}\text { Demographic } \\
\text { Parameter }\end{array}$ & LS & MT & $R_{0}$ & $\mathrm{G}$ & $r_{m}$ & $\lambda$ & $\begin{array}{c}\text { Salinity } \\
\text { (PSU) }\end{array}$ \\
\hline \multirow{3}{*}{$M_{T}^{T}$} & -0.22 & 1.00 & -0.38 & 0.01 & -0.54 & -0.44 & 5 \\
\hline & 0.06 & 1.00 & -0.43 & 0.41 & -0.57 & -0.42 & 20 \\
\hline & 0.14 & 1.00 & -0.18 & 0.50 & -0.32 & -0.18 & 34 \\
\hline \multirow{3}{*}{$\mathrm{R}_{\mathrm{o}}$} & 0.89 & -0.38 & 1.00 & 0.81 & 0.88 & 0.77 & 5 \\
\hline & 0.85 & -0.43 & 1.00 & 0.48 & 0.87 & 0.80 & 20 \\
\hline & 0.80 & -0.18 & 1.00 & 1.60 & 0.71 & 0.55 & 34 \\
\hline \multirow{3}{*}{$G$} & 0.90 & 0.01 & 0.81 & 1.00 & 0.51 & 0.35 & 5 \\
\hline & 0.85 & 0.41 & 0.48 & 1.00 & 0.06 & 0.06 & 20 \\
\hline & 0.81 & 0.49 & 0.60 & 1.00 & -0.01 & -0.10 & 34 \\
\hline \multirow{3}{*}{$r_{m}$} & 0.63 & -0.54 & 0.88 & 0.51 & 1.00 & 0.92 & 5 \\
\hline & 0.45 & -0.57 & 0.87 & 0.06 & 1.00 & 0.93 & 20 \\
\hline & 0.38 & -0.32 & 0.71 & -0.01 & 1.00 & 0.94 & 34 \\
\hline \multirow{3}{*}{$\lambda$} & 0.47 & -0.44 & 0.77 & 0.35 & 0.92 & 1.00 & 5 \\
\hline & 0.41 & -0.42 & 0.80 & 0.06 & 0.93 & 1.00 & 20 \\
\hline & 0.30 & -0.18 & 0.55 & -0.10 & 0.94 & 1.00 & 34 \\
\hline
\end{tabular}




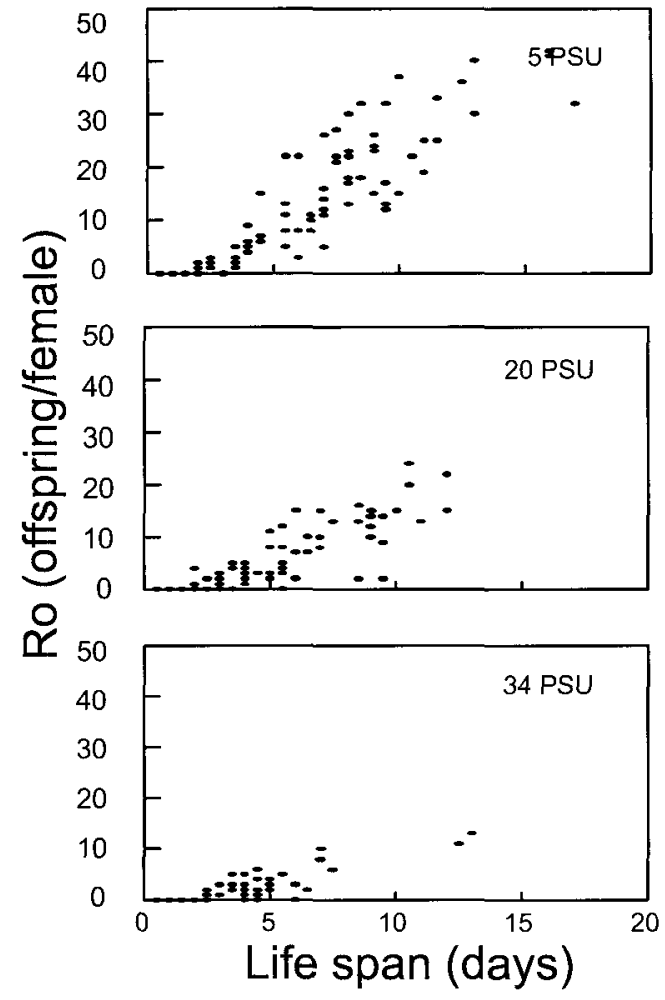

Fig. 3. Co relation pattern between life span and net reproduction rate of Brachionus rotundiformis at different salinities.

mum longevity of $B$. rotundiformis was 17 days at 5 PSU, which was one of the longest life span of the genus Brachionus previously reported so far. Although the maximum life span at 34 PSU (13 days) was highe: than that at 20 PSU ( 12 days), the mean values of ife span at 34 PSU (3.54 days) was much lower than at 20 PSU ( 4.58 days). Thus, life span of the ro ifers decreased with increasing salinity (Table 1).

As mat ration process can not be properly observed in a rotifer. maturation time was estimated by checking the time when a female first produced her egg. The minimum maturation time was $24 \mathrm{hr}$ at $5 \mathrm{PSU}$, and $36 \mathrm{hr}$ at both $20 \mathrm{PSU}$ and $34 \mathrm{PSU}$, and mean maturation time was shorter at 5 PSU than at other salinities (Table 1). This indicates that the rotifer strain we used favo ed lower salinity that was similar to the salinities ( 3.2 to 5.6 PSU) measured at their natural habitat (Song et al., 1999).

The hichest reproduction rate of the rotifer has previously been reported in various rotifer species. They were 4.2-9.1 offspring per female in Synchaeta littoralis (Bosque et al., 2001), 12.8 offspring in $S$.

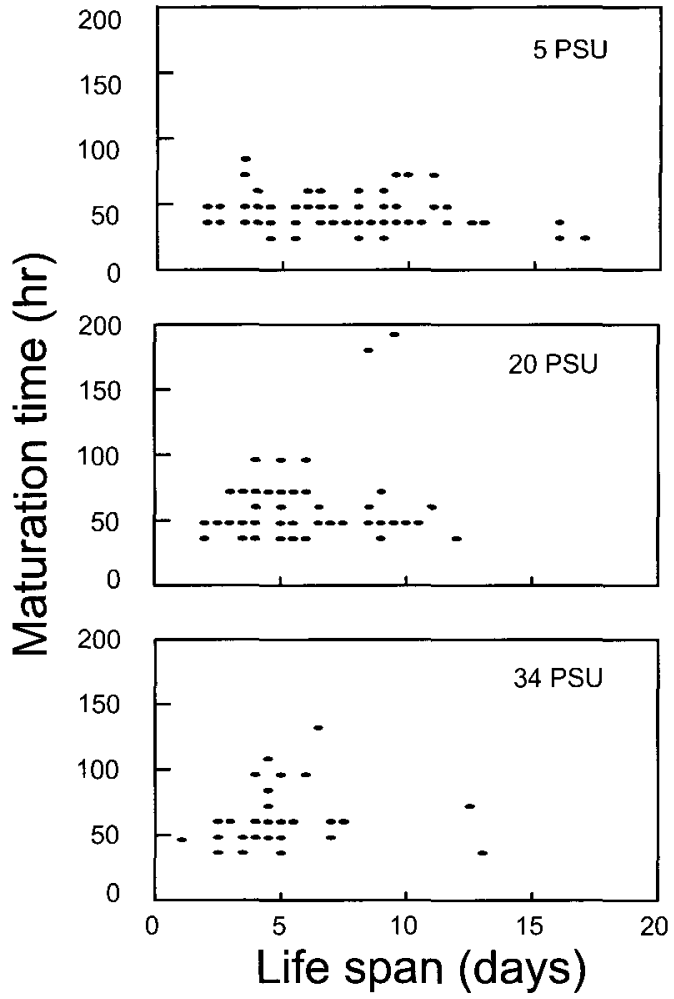

Fig. 4. Correlation pattern between life span and maturation time of Brachionus rotundiformis at different salinities.

cecilia (Oltra et. al., 2000), 28.5 offspring in $B$. plicatilis (Bosque et al., 2001) and 37 offspring in an ultra small type of B. plicatilis (Cabrera et al., 1993). In this study, the maximum offspring produced by a female was 42 at 5 PSU, recording the highest among the values previously known. In addition, there was the tendency of increasing net reproduction rate with decreasing salinity, and significant differences in net reproduction rate of the rotifers were observed among three salinities $(P<0.0001)$. Correlation analysis showed that life span and reproduction rate denoted a high correlation at salinity of 5 PSU $(r=$ 0.90 ), and this correlation was diminished with increasing salinities. Lubzens (1987) reported that rotifer reproduction rate was strongly influenced by the salinity of medium, and Miracle and Serra (1989) insisted that salinity was supposed to have an effect on primary fecundity of rotifer. Other studies indicated that there was an evident relationship between life span and the length of the reproduction period, or life span and fecundity of rotifer (Cabrera et al., 1993, Yoshinaga et al., 2000).

Yoshinaga et al. (2000) proposed that the rotifers 
had the fastest reproduction rate of all metazoans. The minimum generation length recorded in this study was 1.5 day at both 5 PSU and 34 PSU. Mean generation length was significantly different at 5 PSU vs. $34 \mathrm{PSU}$ and $20 \mathrm{PSU}$ vs. $34 \mathrm{PSU}$, but not at $5 \mathrm{PSU}$ vs. $20 \mathrm{PSU}$, and any tendency due to salinity was not re- cognized. Innate capacity for increase $\left(r_{m}\right)$ and finite rate of increase $(\lambda)$ are two main ecological indices that reflect the natural potential of a population for growth and multiplication. Previous researchers calculated high innate capacity for increase in rotifers. For instance, 0.7-1.4 individuals per day for $B$. plicatilis (Hoff and Snell, 1987) and 0.84-1.12 individuals for $S$. cecilia (Oltra et al., 2000) had been proposed as notable reproductive potential in rotifer. Our results also revealed higher values of $r_{m}$ and $\lambda$ at 5 PSU than at other salinities. $r_{m}$ ranged $0.46-$ 1.56 individuals per day and $\lambda$ was $1.70-6.67$ individuals per day depending on salinity. ANOVA indicated significant difference between $r_{m}$ at all different salinities, and between $\lambda$ at either 5 PSU vs. 20 PSU or 5 PSU vs. 34 PSU (Table 1). Correlation analysis did not show evident relationship between life span and these intrinsic parameters $\left(r_{m}\right.$ and $\left.\lambda\right)$ of the rotifer even at low salinity (Table 2). However, since there was a decreasing tendency in both parameters and correlation values with salinity increase, the effect of salinity was evident on these parameters. On the other hand, some studies suggested that genetic parameters such as strain, type and origin of clones can influence the effect of environmental factors on rotifer life span (Miracle and Serra, 1989; Cabrera et al., 1993; Treece and Davis, 2000 and Bosque et al., 2001). Based on these, we used clonal population for this study to avoid such potential problems. As a result, we confirmed the studies of Cabrera et al. (1993) and Fielder et al. (2000) who found higher growth rate of $B$. rotundiformis at lower salinity. This can be also explained by the "rate of living" theory (Speakman et al., 2002) that the shorter life time at higher salinities can be a function of more energy expenditure for adaptation to those unexpected conditions.

Data extracted from measuring the demographic parameters have provided some basic supportive information about cultural capabilities of this rotifer. As the strain we studied has high potentiality for survival and reproduction at low salinity, we can use it as a first feed organism for freshwater fish aquaculture in the future.

\section{Acknowledgements}

We thank Dr. Terry W. Snell (Georgia Institute of Technology, USA) and Dr. S.Y. Hong (Pukyong National University, Korea) for critical reading of the manuscript and helpful comments. This research is financially supported by the graduate student scholarship (to R.M. Viayeh) from the Brain Korea 21 Project in 2003 and research fund (to Dr. C.B. Song) from the Korean Ministry of Maritime Affairs and Fisheries.

\section{References}

Bosque, T., R. Hernandez, R. Perez and R. Oltra. 2001. Effects of salinity, temperature and food level on the demographic characteristics of the sea water rotifer Synchaeta littoralis Rousselet. J. Exp. Biol. Ecol., 258, 55-64.

Cabrera, T., S.B. Hur and H.J. Kim. 1993. Life span and fecundity of three types of rotifer, Brachionus plicatilis by an individual culture. Bull. Kor. Fish. Soc., 26(6), 511-518.

Enesco, H., A. McTavish and R. Garberi. 1990. Spontaneous activity level and life span in rotifers: lack of support for the rate of living theory. Gerontol., 36, 256-261.

Fielder, D.S., G.J. Purser and S.C. Battaglene. 2000. Effect of rapid changes in temperature and salinity on availability of the rotifers Brachionus rotundiformis and Brachionus plicatilis. Aquaculture, 189, 85-99.

Fu, Y., K. Hirayama and Y. Natsukari. 1991a. Morphological differences between two types of the rotifer Brachionus plicatilis O.F. Müller. J. Exp. Mar. Biol. Ecol., 151, 29-41.

Fu, Y., K. Hirayama and Y. Natsukari. 1991b. Genetic divergence between $S$ and $L$ type strains of the rotifer Brachionus plicatilis O.F. Müller. J. Exp. Mar. Biol. Ecol., 151, 43-56.

Fukusho, K. 1989. Biology and mass production of the rotifer, Brachionus plicatilis. Int. J. Aquacult. Fish Technol., 1, 232-240.

Hirayama, K. and I.M.F. Rumengan. 1993. Fecundity pattern of S and L type rotifers Brachionus plicatilis. Hydrobiologia, 255/256, 153-157.

Hoff, F.H. and T.W. Snell. 1987. Plankton Culture Manual. Florida Aqua Farms Inc. Publications, pp. 38-75.

Krebs, C.J. 1978. Ecology; The experimental analysis of distribution and abundance. Harper Int. Ed., N.Y., U.S.A., pp. 678.

Lubzens, E. 1987. Raising rotifers for use in aquaculture. Hydrobiologia, 147, 245-255.

Miracle, R. and M. Serra. 1989. Salinity and temperature influence in rotifer life history characteristics. Hydrobiologia, 186/187, 81-102.

Oltra, R. and R. Todoli. 1997. Effects of temperature, salinity and food level on the life history traits of 
the marine rotifer Synchaeta cecilia valentina, n. sub sp. J. Plankton Res., 19, 693-702.

Oltra, R., R. Todoli, T. Bosque, L.M. Lubian and J.C. Navarr ). 2000. Life history and fatty acid composition of the marine rotifer Synchaeta cecilia fed different algae. Mar. Ecol. Prog. Ser., 193, 125-133.

Park, H.G. and S.B. Hur. 1996a. Resting egg production of six strains of Korean rotifer, Brachionus plicatilis. J. Aqliacult., 9(3), 195-203.

Park, H.G. and S.B. Hur. 1996b. Effect of temperature and salinity on production of resting egg in Korean rotifer, Brachionus plicatilis. J. Aquacult., 9(4), 321327.

Rumengan, I.F.M., V. Warouw and A. Hagiwara. 1998. Morphology and resting egg production potential of the tropical ultra-minute rotifer Brachionus rotundiformis (Manado strain) fed different algae. Bull. Fac. Fish. Vagasaki Univ., 79, 31-36.

Sawada, M and J.C. Carlson. 1987. Association between lipid peroxidation and life-modifying factors in rotifers. J. Gerontol., 42(4), 451-456.

Smith, C.V. and H.E. Enesco. 1982a. The effect of temperatue and of dietary restriction on life span and reproduction in the rotifer Asplanchna brightwelli. Exp. Gerontol., 17, 255-262.
Smith, C.V. and H.E. Enesco. 1982b. Maternal age and life span don't influence longevity in the rotifer Asplanchna brightwelli. Exp. Gerontol., 17, 263-266.

Song, C.B., Y.H. Kim, J. Lee and S. Rho. 1999. Size variation and cyclomorphosis of the rotifer, Brachionus rotundiformis, isolated from Cheju Island, Korea. J. Aquacult., 12(4), 267-274.

Speakman, J., C. Selman, J.S. Mclaren and E.J. Harper. 2002. Living fast, dying when? The link between aging and energetics. J. Nutr., 132 (6 Suppl. 2), $1583 \mathrm{~s}-1597 \mathrm{~s}$.

Treece, G.D. and A. Davis. 2000. Culture of small zooplanktons for the feeding of larval fish. South. Reg. Aquacult. Center Publ., 701, pp. 7.

Tukey, J.W. 1953. The problem of multiple comparisons. Department of Statistics, Princeton University. (unpublished)

Yoshinaga, T., A. Hagiwara and K. Tsukamoto. 2000. Effect of periodical starvation on the life history of Brachionus plicatilis O.F. Müller (Rotifera): a possible strategy for population stability. J. Exp. Mar. Biol. Ecol., 253, 253-260.

(Received January 2004, Accepted March 2004) 